\title{
Alfabetização científica e a construção de concepções no contexto de formação de professores
}

DOI 10.26512/Ic.v24i0.21588

\author{
Patrícia da Silva Sessa \\ Universidade Federal do $A B C$ \\ Centro de Ciências Naturais e Humanas \\ patricia.sessa@ufabc.edu.br \\ Júlio Carvalho de Paiva \\ Universidade Federal do $A B C$ \\ Centro de Ciências Naturais e Humanas \\ julio.carvalho@ufabc.edu.br \\ Emile Ferreira da Cunha Casasco \\ Universidade Federal do $A B C$ \\ Centro de Ciências Naturais e Humanas \\ emilefcc@hotmail.com \\ João Rodrigo Santos da Silva \\ Universidade Federal do $A B C$ \\ Centro de Ciências Naturais e Humanas \\ joao.rodrigo@ufabc.edu.br
}

\section{Resumo}

O presente artigo investiga as concepções sobre Alfabetização Científica (AC) de professores de Ciências de 6으 ao 9a ano da rede pública de um município do interior paulista em um contexto de formação continuada. Os dados foram coletados através de um questionário com perguntas abertas sobre a atividade da formação, as concepções dos professores antes e depois dessas atividades. Como resultados, alguns professores apresentaram mudanças de suas concepções sobre Alfabetização Científica no que diz respeito à necessidade de métodos científicos, nos permitindo 
apontar a necessidade de continuidade de pesquisas que contemplem esse tipo de abordagem bem como as formações continuadas de professores.

Palavras-chave: Alfabetização Científica; Formação de Professores; Formação continuada; Ensino de Ciências.

\section{Abstract}

This article investigates the conceptions of scientific literacy of elementary school science teachers from 6th until 9th of Brazilian elementary school at a city in São Paulo state in the context of continuous formation. The data were collected on the activity of training through a questionnaire with open questions where the teachers' conceptions were formally collected before and after the execution of activities. As a result, some teachers changed their conception related to the scientific literacy regarding the need of scientific methods, allowing us to the point out the need for further research that address this kind of approach as well as continuing teacher training.

Keywords: Scientific literacy; Teacher training; Continuing education, Science teaching.

\section{Resumen}

El presente artículo investiga las concepciones sobre Alfabetización Científica (AC) de profesores del 6o al go año de la red pública de una municipalidad del interior de São Paulo en un contexto de formación continuada. Los datos fueron colectados desde un cuestionario abierto sobre una actividad de formación. Como resultados, algunos profesores presentaron cambios en sus concepciones sobre Alfabetización Científica en lo que se refiere a la necesidad de métodos científicos, permitiendo apuntar la necesidad de continuidad de investigaciones que contemplen ese tipo de enfoque así como las formaciones continuadas de profesores.

Palabras clave: Alfabetización Científica; Formación de profesores; Formación continua; Enseñanza delas Ciencias.

\section{Résumé}

Cet article est une étude sur les conceptions de culture scientifique des enseignants en sciences de la Ge à la 9e année du réseau public d'une municipalité de l'intérieur de São Paulo dans un contexte de formation continué. La collecte de données a été faite à partir d'un questionnaire avec des questions ouvertes sur l'activité de formation, les conceptions des enseignants avant et après ces activités. Comme résultats, certains 
enseignants ont présenté des changements de leurs conceptions de la culture scientifique en ce qui concerne la nécessité des méthodes scientifiques, ce qui nous a permis de souligner le besoin de continuité de la recherche qui envisage ce type d'approche ainsi que la formation continue des enseignants.

Mots-clés: Alphabétisation scientifique; La formation des enseignants; Éducation permanente; Enseignement des sciences.

\section{Introdução}

Dentre diversas inquietações, a Alfabetização Científica (AC) chama a atenção pelo seu caráter transformador na sociedade por indicar uma reflexão crítica da ciência e uma mudança de atitude dos cidadãos (Shamos, 1995; Bauer, 1992). Contudo, a definição do que seria AC pode variar de acordo com o referencial teórico.

Alguns autores (Chassot, 2002; Fourez, 2003; Bybee, 1997; Shamos, 1995; Sasseron \& Carvalho, 2008) discutem exatamente sobre essa dificuldade em estabelecermos um consenso sobre a definição de $\mathrm{AC}$, sobretudo devido à tradução do termo original em inglês scientific literacy para o português, que pode ser entendido como letramento científico. Assim, nesse trabalho, será utilizado o discurso referente à temática definido pela National Science Education Standards (1996, p. 35):

É o conhecimento e a compreensão de conceitos e processos científicos necessários para a tomada de decisão pessoal, participação nos assuntos cívicos, culturais e econômicos. Também inclui tipos específicos de capacidades. [...] isso significa que uma pessoa tem a capacidade de descrever, explicar e prever fenômenos naturais. Alfabetização Científica implica ser capaz de ler com compreensão artigos sobre ciência na imprensa popular e se engajar em conversas sociais sobre a validade das conclusões. Alfabetização Científica implica que uma pessoa pode identificar questões científicas de âmbito nacional e local e tomar decisões e posições expressas que são cientificamente e tecnologicamente informadas. Um cidadão cientificamente alfabetizado deve ser capaz de avaliar a qualidade da informação científica sobre a base na sua origem e os métodos utilizados para gerá-la. Alfabetização Científica implica igualmente a capacidade de avaliar argumentos baseados em evidências e aplicar as conclusões de tais argumentos apropriadamente.

Neste contexto, a Alfabetização Científica está ligada ao conhecimento científico e, principalmente, em suas interlocuções na sociedade. Segundo Araújo e colaboradores (2006), é possível convivermos em nossa sociedade com três estágios de Alfabetização Científica: no primeiro deles, a ciência é um mito, feita por gênios, no qual o processo de produção do saber científico é idealizado e distorcido; no segundo, a ciência é 
representada como uma construção humana, coletiva e desmistificada como verdade absoluta; em um terceiro estágio, a ciência é representada como um sistema de conhecimento, imagem típica da comunidade científica. Esses autores consideram que, para que a sociedade seja considerada alfabetizada cientificamente, é imprescindível que o cidadão esteja pelo menos no segundo estágio apresentado acima e, portanto, se faz necessária a inserção da cultura científica na cultura geral.

Penick (1998) aponta um estudo sobre as relações de alfabetização das ciências dentro do ensino de biologia. No estudo do Currículo de Ciências Biológicas (1993) ${ }^{1}$, foram identificados quatro níveis hierárquicos da alfabetização biológica: nominal, funcional, estrutural e multidimensional. Essa classificação é bem semelhante à apresentada por Cachapuz (2011). Para Bybee ${ }^{2}$ (1997, apud Cachapuz 2011), existe uma gradação na construção e classificação da alfabetização científica. Ao estabelecer uma relação entre as duas classificações, têm-se: a alfabetização científica nominal, quando se há um reconhecimento dos termos, mas não se entende o seu uso; a alfabetização científica funcional quando se consegue relacionar o nome à função do termo científico; a alfabetização científica estrutural, relacionada à formulação de conceitos e explicações com base nos conhecimentos científicos fundamentados; e por fim, a multidimencional, quando há uma aplicação do conhecimento e uma percepção global da ciência.

Outro aspecto relevante é a descontrução de que a Alfabetização Científica está atrelada ao método científico (Bauer, 1992). Neste cenário, o autor destaca a importância de se aprender ciências para as pessoas construírem um senso crítico referente a este conhecimento. $\mathrm{O}$ autor ainda apresenta argumentos comuns sobre a alfabetização científica e quão o conhecimento científico pode contribuir para o entendimento da ciência e à formação dos cidadãos (p. 12-13):

1. Conhecer a ciência permite que as pessoas tomem melhores decisões em uma era científica;

2. Compreensão da tecnologia moderna traz o bem econômico e assim ajuda a segurança nacional;

3. O conhecimento científico substitui a superstição;

\footnotetext{
${ }^{1}$ BIOLOGICAL SCIENCES CURRICULUM STUDY. Developing Biological Literacy. Colorado Springs, CO: The Author, 1993. Referência citada por PENICK, J.E. Ensinando "alfabetização científica". Educar em Revista, v. 14, p. 91-113, 1998.

2 BYBEE, R. (1997). Towards an Understanding of Scientific Literacy. Em Gräber, W. e Bolte, C. (Eds.) Scientific Literacy. Kiel: IPN. Referencia usada por CACHAPUZ, A. et al. A necessária renovação do ensino das ciências. São Paulo: Cortez, 2011.
} 
4. Como ocorre o aprendizado e o pensamento científico, isto é, em relação às consequências imprevisíveis das ações, então nosso comportamento se tornará mais racional;

5. A familiaridade com o método científico conduzirá a uma atitude mais ética.

Apesar de elencar tais características, Bauer (1992) indica que os dois primeiros argumentos são inquestionáveis, contudo, os outros três não podem ser mensurados como condições para a alfabetização científica. Um dos grandes problemas é acreditar que o método científico transformará o pensamento dos cidadãos. Para o autor, a ciência não pode ser definida somente com base em uma sequência metodológica e nem pode ser vista como tal.

Um dos aspectos apontados por Cachapuz e colaboradores (2011) é exatamente essa relação da alfabetização científica com a formação do futuro cientista. Para os autores, não se deve estabelecer essa relação, pois a alfabetização científica está atrelada à formação de cidadãos. Assim, a única relação possível é a imersão numa cultura científica de investigação. Essa imersão pode ocorrer tanto na escola quanto na universidade.

Nesse sentido, mais do que elencar tais deformações, Gil Perez et al (2001) chamam atenção para apontar não uma única resposta, mas várias alternativas à reflexão docente que constituem os respectivos pontos de consenso.

Esses pontos se configuram nas "características essenciais do trabalho científico": (a) apesar de constituir um "método", a metodologia científica não se resume a regras a aplicar; (b) recusa de um empirismo que concebe os conhecimentos como resultados de induções, pois os paradigmas conceituais consistem na origem e no fim do conhecimento científico; (c) pensamento divergente atribuído pela investigação e pelo trabalho com hipóteses; (d) coerência global, atribuindo validade às hipóteses, confrontando e revisando suas teses; e (e) caráter social do conhecimento científico.

Ao considerarmos tais questões, compreendemos que a Alfabetização Científica se centra no indivíduo e que a cultura exige um olhar sistêmico de grupos e instituições para a difusão social da ciência (Vogt \& Polino, 2003). Assim, é importante que a Alfabetização Científica já ocorra no Ensino Fundamental, estimulando a curiosidade dos estudantes para o mundo que os rodeia (Roden \& Ward, 2010). Segundo Roden e Ward (2010), existe uma lacuna na compreensão da ciência entre diferentes grupos de pessoas. Esse entendimento do que é ciência e de como ela é construída pode ter criado um distanciamento social que é refletido no ensino de ciências, justamente pela forma como este ensino é debatido. 
Neste sentido, é importante ressaltar que a educação não deve ser tida como uma doutrinação, mas sim como uma formação crítica de cidadãos influenciando no comportamento social. Assim, reconhece-se a ciência como uma atividade humana, assim como as outras, inseridas na sociedade com um conhecimento específico entrelaçado a ela (Bauer, 1992). Assim surge um questionamento: porque a ciência ainda está distante do conhecimento social?

No âmbito de uma educação científica, o desenvolvimento do conhecimento científico precisa se aproximar dos interesses e da compreensão dos alunos para que se ajuste melhor às necessidades da sociedade, suscitando uma visão de ciência como uma das formas de compreender o mundo. Trata-se de consenso que precisa ecoar nas escolas de Educação Básica de forma a estabelecermos uma educação científica que oportunize aos estudantes não somente a apropriação de conceitos, mas sobretudo, de atitudes voltadas a uma perspectiva global que integrem a sociedade planetária através da satisfação das necessidades básicas deste coletivo (Lemke, 2006).

As escolas e os sujeitos nela inseridos podem ser o cenário ideal para um debate sobre Alfabetização Científica. Segundo Shamos (1995), existe um movimento para desfazer a crise no ensino de ciências e o caminho para reverter esse quadro é o uso da alfabetização científica nesses espaços.

Nessa perspectiva, é importante associar a educação científica nas escolas não apenas com o entendimento de ciências, mas relacioná-la com questões políticoeconômicas, sociais e tecnológicas. Esse movimento transforma o ensino de ciências em uma ferramenta para a compreensão do conhecimento científico e como ele está inserido na sociedade.

Neste espaço social, a ação dos professores é essencial para a construção do pensamento científico dos estudantes. Por isso, apontamos a importância do professor considerar a Alfabetização Científica ao planejar suas ações e suas práticas em sala de aula. Em se tratando da ação docente, a finalidade desse trabalho não está na tessitura de críticas às suas práticas usuais, mas na discussão sobre o lugar que a alfabetização científica ocupa na formação de professores.

Uma das modalidades de formação docente é a formação de professores em exercício. Para tanto, é importante que o professor reconheça que está em contínua formação para que, a partir disso, se permita compreender sua prática e sua identidade docente. Outro destaque é entender que a formação docente é algo complexo, devendo considerar a comunidade no qual está inserido; conhecer os cenários que vieram e onde 
estão para entender onde se pretende chegar e, principalmente, a formação deve assumir o desenvolvimento de atitudes e emoções para que o desenvolvimento profissional seja contínuo de fato (Imbernón, 2010).

Dada sua complexidade, a formação continuada de professores apresenta alguns aspectos que merecem destaque. O primeiro deles se refere ao confronto entre a academia e a prática do professor. Apesar do aspecto idiossincrático da formação de professores, existe uma necessidade de aproximação entre esses espaços para um melhor diálogo na construção do conhecimento e da realidade do ensino (Gatti, 2011). Outro aspecto importante é a efetiva formação de professores em exercício. Neste quesito, "os conhecimentos adquirem sentido ou não, são aceitos ou não, incorporados ou não, em função de complexos processos não apenas cognitivos, mas também socioafetivos $e$ culturais" (Gatti, 2011, p.171).

Esses dois aspectos assinalam essa problemática da formação de professores em exercício: na centralização das formações em conceitos 'ideais', na perspectiva de cenário ideal para o ensino; na centralização de aspectos cognitivos individuais, ligados à ideologia de quem executa o processo formativo; na centralização de abordagens descontextualizadas. Assim, por vezes, as formações esquecem das representações sociais e culturais de cada grupo, da individualidade dos sujeitos envolvidos no processo formativo (Gatti, 2011; Imbernon, 2010).

Os espaços para a formação de professores podem ser considerados privilegiados e prioritários para a reflexão, discussão e análise de práticas para uma construção de conhecimento. A partir desse pressuposto, e das ideias relacionadas à Alfabetização Científica, este trabalho busca investigar o discurso construído pelos sujeitos (professores em formação continuada) numa perspectiva sociocultural, e sobretudo, observar atentamente a produção de práticas que se debrucem sobre a Alfabetização Científica, no contexto real de ensino.

Uma forma de analisar tais questões é através de eixos estruturantes e indicadores de Alfabetização Científica. Segundo Sasseron e Carvalho (2008), a ideia dos Eixos Estruturantes da Alfabetização Científica pode auxiliar a planejar aulas que tragam para as situações de ensino uma abordagem mais geral e coesa das ciências. Os Eixos Estruturantes da Alfabetização Científica surgiram da análise de referenciais da área de Ensino de Ciências que apresentavam ideias e habilidades a serem desenvolvidas com o intuito de que a Alfabetização Científica pudesse estar em processo e tais eixos possam ser analisados através de indicadores de Alfabetização Científica (Sasseron, 2015). 
Nesse sentido, nossa investigação tem o objetivo de evidenciar as concepções sobre Alfabetização Científica e como estas reverberam nas práticas cotidianas de professores de Ciências do Ensino Fundamental II de uma rede municipal de ensino, a partir das falas e registros destes professores durante uma formação continuada.

\section{Metodologia}

A pesquisa foi desenvolvida em um contexto de formação continuada de professores de uma rede pública municipal de ensino. Para sua realização, fez-se uso de uma abordagem qualitativa, proporcionando descrições detalhadas de pessoas em ação ou práticas sociais. Destaca-se neste aspecto que os dados amostrais representam falas e ações apresentadas na formação de professores (Lankshear \& Knobel, 2008).

\section{0 curso e o grupo amostral}

O curso de formação continuada de professores de Ciências foi realizado em parceria com uma Prefeitura de um município paulista, desenvolvido no horário de serviço dos professores da rede municipal de ensino. Os encontros foram realizados uma vez por mês, durante cinco meses. O público atendido correspondeu a 29 (vinte e nove) professores efetivos da rede, os quais tiveram suas identidades preservadas, sendo identificados por meio dos símbolos P1 a P29.

No primeiro encontro foram detalhados a estrutura e os conteúdos do curso, além de realizadas atividades contemplando as temáticas de Alfabetização Científica, de acordo com as matrizes curriculares do município.

Nessa perspectiva, o primeiro e segundo encontros abordaram temas relacionados à Alfabetização Científica e, com base em modelos científicos propostos, foram discutidos modelos gerais, aplicabilidades e particularidades relacionadas com sua produção no ambiente de ensino. Tendo em vista a panorâmica de estudo proposta, foi realizada a primeira atividade em grupo que consistia no desenvolvimento de sequências didáticas que utilizassem do conceito de Alfabetização Científica até então abordadas. 0 desenvolvimento de sequências didáticas tinha como intuito promover a reflexão dos docentes enquanto produtores/organizadores de suas atividades de ensino.

Em seguida, trabalhamos com a temática CTSA - Ciência, Tecnologia Sociedade e Ambiente, no sentido de estabelecermos relações conceituais entre o ensino de Ciências e o enfoque CTSA. Por fim, como forma de sistematizar os assuntos abordados ao longo 
deste período, no quinto encontro foi realizada a conclusão do tema relacionado à divulgação científica, enfatizando o diálogo entre os temas, os docentes e a prática de ensino.

$\mathrm{Na}$ etapa final dos encontros, resgatamos todas as sequências didáticas em um caderno de atividades práticas possibilitando a continuidade do trabalho pedagógico. As sequências foram baseadas na Alfabetização Científica; o enfoque CTSA e notícias de revistas e jornais com temáticas locais para demonstrar a inserção do conhecimento científico no cotidiano. Para este estudo foram analisadas somente as atividades relacionadas à Alfabetização Científica.

\section{Procedimento de coleta de dados}

A coleta de dados ocorreu a partir de questionários e de registro de vídeo, alicerçada no quadro teórico-dialógico, uma vez que as manifestações do comportamento humano - como as expressões verbais e suas mensagens - são elementos que devem ser considerados para compreender as práticas educativas e, mais precisamente, o processo de ensino-aprendizagem. Vale ressaltar que os diálogos e discussões desenvolvidos ao longo de todo o curso foram registrados e consentidos pelos participantes da pesquisa, os quais assinaram um termo de consentimento para a coleta de dados.

Os questionários utilizados continham perguntas abertas. As questões abertas (ou subjetivas) permitem que os entrevistados apresentem seus pontos de vista livremente de maneira a possibilitar que os professores amostrados expusessem suas concepções e representações sobre o tema (Lankshear \& Knobel, 2008).

Os questionários foram aplicados em três momentos distintos do curso, sendo o primeiro e o último referentes, respectivamente, às sondagens inicial e final, e, portanto, as questões apresentadas em ambos eram as mesmas: 1. O que é Alfabetização Científica? 2. É possível ensinar através da Alfabetização Científica? Como isso pode ser feito? Ao finalizarmos as atividades sobre Alfabetização Científica, o questionário foi configurado de modo a avaliar a formação e as influências por ela exercida ao grupo de professores em formação, tendo somente uma questão: De que forma as ideias sobre Alfabetização Científica podem auxiliar na sua prática como professor(a)? 


\section{Análise dos dados}

Os dados do presente trabalho foram analisados sob a luz da análise textual discursiva proposta por Moraes e Galiazzi (2006). Segundo os autores, esse modelo de análise de dados é uma abordagem que transita entre duas formas consagradas de análise na pesquisa qualitativa que são a análise de conteúdo e a análise de discurso.

Na análise textual discursiva (Moraes, 2003; Moraes \& Galiazzi, 2006), o processo se inicia com uma unitarização em que os textos são separados em unidades de significado. Depois da realização desta unitarização, passa-se a fazer a articulação de significados semelhantes em um processo denominado de categorização. Neste processo reúnem-se as unidades de significado semelhantes, podendo originar vários níveis de categorias de análise. As categorias foram construídas a partir dos dados coletados (i.e., a posteriori). Por fim, a análise se desloca do empírico para a abstração teórica, produzindo textos que dialogam com referenciais teóricos.

Vale explicitar que, neste trabalho, procedemos metodologicamente com a organização dos dados a partir das observações das interações durante o curso e das respostas dos professores aos questionários, buscando o significado das mensagens neles contidos. Assim, as concepções de professores foram construídas baseadas em subcategorias $a$ priori: Alfabetização para desenvolvimento de conceitos, Alfabetização para a construção de conceitos próprios e Entendimento da Ciência, seu uso, seu vocabulário e os contextos do conhecimento.

\section{Resultados}

A primeira questão busca evidenciar as concepções dos professores a respeito do que eles compreendem como Alfabetização Científica. Ao analisarmos as respostas dos professores, que foram elaboradas tanto no primeiro momento - sondagem inicial quanto no terceiro momento - sondagem final, organizamos três grandes categorias, a saber: i. Alfabetização para desenvolvimento de conceitos; ii. Alfabetização para a construção de conceitos próprios; e iii. Entendimento da ciência, seu uso, seu vocabulário e os contextos do conhecimento. Esses dados podem ser vistos na tabela 01.

A categoria mais citada relaciona a Alfabetização Científica com entendimento de ciências, seu uso e os contextos do conhecimento, sendo que o número de respostas obtidas para esta categoria praticamente se manteve ( 12 na sondagem inicial e 11 na sondagem final). 
A segunda categoria mais citada relaciona Alfabetização Científica com a aquisição de terminologias e vocabulário próprios da ciência, bem como seus métodos. Essa categoria apresentou redução no número de respostas, passando de 11 para 7. A terceira categoria representa a concepção de Alfabetização Científica como forma de conferir significado aos conceitos, desenvolver nos estudantes habilidades e competências de se entender a ciência; nesta categoria, o número de citações subiu de um para seis (Tabela 01).

A segunda questão contempla a possibilidade de se alfabetizar cientificamente nas escolas, sendo que no questionário aplicado antes do curso todos os professores alegaram que era possível realizar tal tarefa. Ao considerar a asserção, os professores foram questionados como seria possível ensinar por meio da Alfabetização Científica. Neste questionamento, somente um professor não justificou como poderia alfabetizar cientificamente; os demais relataram diferentes possibilidades (Tabela 02).

Tabela 01: Concepções dos professores sobre o que é Alfabetização Científica separados na frequência de categorias.

\begin{tabular}{|c|c|c|c|}
\hline Categoria & Subcategoria & $\begin{array}{l}\text { Respostas } \\
\text { antes do } \\
\text { curso }\end{array}$ & $\begin{array}{l}\text { Respostas } \\
\text { pós-curso }\end{array}$ \\
\hline \multirow{2}{*}{$\begin{array}{l}\text { Alfabetização para } \\
\text { desenvolvimento de conceitos }\end{array}$} & Método científico & 5 & 1 \\
\hline & Vocabulário científico & 6 & 6 \\
\hline \multirow{2}{*}{$\begin{array}{l}\text { Alfabetização para a construção de } \\
\text { conceitos próprios }\end{array}$} & Dar significado a conceitos & 0 & 5 \\
\hline & $\begin{array}{l}\text { Desenvolvimento de } \\
\text { competências e habilidades }\end{array}$ & 1 & 1 \\
\hline \multirow{3}{*}{$\begin{array}{l}\text { Entendimento da ciência, seu uso, } \\
\text { seu vocabulário e os contextos do } \\
\text { conhecimento. }\end{array}$} & $\begin{array}{l}\text { Compreensão do uso de } \\
\text { ciências e tecnologia }\end{array}$ & 6 & 6 \\
\hline & $\begin{array}{l}\text { Cidadão crítico, } \\
\text { reflexivo, atuante na } \\
\text { sociedade }\end{array}$ & 2 & 2 \\
\hline & $\begin{array}{l}\text { Incorporação de saberes } \\
\text { inerentes à ciência }\end{array}$ & 4 & 3 \\
\hline
\end{tabular}

Ao final da formação, para aprofundarmos a questão relativa à contribuição da $A C$ à prática docente, propusemos a seguinte questão avaliativa: “De que forma as ideias sobre Alfabetização Científica podem auxiliar a sua prática como professor (a)?” (Tabela 03). 
A maior parte dos professores respondeu que a Alfabetização Científica auxilia na prática docente no que diz respeito à oportunidade de reflexão sobre as finalidades do ensino de Ciências. Outros dois grupos apontaram que os conceitos de Alfabetização Científica ajudam a discutir a importância dos temas na formação dos alunos e no planejamento das atividades em sala. Quatro docentes não responderam tal questionamento.

Tabela 02: Possibilidades para ensinar através da AC.

\begin{tabular}{|l|l|l|l|}
\hline \multirow{4}{*}{ Categoria } & \multicolumn{1}{|c|}{ Subcategoria } & $\begin{array}{c}\text { Respostas } \\
\text { antes do } \\
\text { curso }\end{array}$ & $\begin{array}{c}\text { Respostas pós- } \\
\text { curso }\end{array}$ \\
\hline \multirow{3}{*}{ Recursos } & Uso de tecnologia & 1 & 0 \\
\cline { 2 - 5 } & Desde que tenha recurso na escola & 2 & 0 \\
\hline \multirow{4}{*}{ Eodelos de aula } & Uso de sequência didática & 0 & 2 \\
\cline { 2 - 5 } & Aulas práticas e experimentais & 4 & 1 \\
\cline { 2 - 5 } & Aulas teóricas e práticas & 0 & 1 \\
\hline & Contextualização & 7 & 9 \\
\cline { 2 - 5 } & Resolução de problemas & 2 & 0 \\
\cline { 2 - 5 } & Variando estratégias & 3 & 5 \\
\cline { 2 - 5 } & Lendo e interpretando dados & 2 & 0 \\
\cline { 2 - 5 } & Motivando o aluno & 1 & 1 \\
\hline Perfil do professor & Atitude do professor & 0 & 3 \\
\hline Modelo de ciência & Desmistificando o cientista & 1 & 1 \\
\hline
\end{tabular}

Em meio às respostas, evidenciamos que um professor considera a importância do trabalho alicerçado na $\mathrm{AC}$, mas não assume que pode influenciar em sua própria prática:

"A Alfabetização Científica, vista como a introdução ao mundo científico, possibilita ao professor ter a percepção da iniciação científica do aluno, de que forma realizar este processo, da importância deste processo a e expor isto ao aluno, considerando a vida cotidiana e as experiências do aluno." P10 
Outros dez professores fazem referência ao professor como sujeito oculto, não necessariamente sendo ele o ator da prática:

"Acrescentam uma nova perspectiva para o trabalho em sala de aula." P14

"É importante para dar foco à condução das atividades em sala de aula." P5

Tabela 03. Números de professores e seus depoimentos representando as categorias.

\begin{tabular}{|l|l|l|}
\hline \multicolumn{1}{|c|}{ Categoria } & $\begin{array}{c}\text { No de } \\
\text { professores }\end{array}$ & \multicolumn{1}{c|}{ Depoimentos } \\
\hline No planejamento & 4 & $\begin{array}{l}\text { "Podem ajudar no planejamento e organização das atividades } \\
\text { propostas." P1 } \\
\text { "Podem auxiliar, na elaboração de atividades visando a } \\
\text { Alfabetização Científica." P13 }\end{array}$ \\
\hline Na prática & 8 & $\begin{array}{l}\text { "Na reflexão sobre a minha prática e na elaboração das } \\
\text { sequências didáticas." P3 } \\
\text { "As ideias sobre Alfabetização Científica já são parte da minha } \\
\text { prática pedagógica, mesmo de maneira implícita." P11 }\end{array}$ \\
\hline $\begin{array}{l}\text { Na interação e } \\
\text { formação do } \\
\text { aluno }\end{array}$ & $\begin{array}{l}\text { "Obs.: não fiz a leitura do texto. Auxilia no sentido em que } \\
\text { deixamos de ver a ciência como mero conteúdo, mas a } \\
\text { formação do aluno em seu processo de conhecimento social, } \\
\text { histórico e na formação de um ser mais humanizado." P7 } \\
\text { "A Alfabetização Científica, vista como a introdução ao mundo } \\
\text { científico possibilita ao professor ter a percepção da iniciação } \\
\text { científica do aluno, de que forma realizar este processo, da } \\
\text { importância deste processo e expor isto ao aluno, } \\
\text { considerando a vida cotidiana e as experiências do aluno." P10 } \\
\text { "As ideias propostas fortalecem a capacidade de interagir com } \\
\text { os alunos através dos diferentes caminhos para a realização da } \\
\text { Alfabetização Científica." P18 }\end{array}$ \\
\hline
\end{tabular}

Tais declarações demonstram que os professores não corroboram o discurso em sua prática cotidiana de docência, ao contrário de outros sete professores, com respostas da natureza:

"As ideias sobre Alfabetização Científica já são parte da minha prática pedagógica, mesmo de maneira implícita." P11

"Me senti motivada a explorar mais o tema para introduzir na prática pedagógica." P20. 


\section{Discussão}

As respostas referentes à conceituação de $\mathrm{AC}$ pelos professores cursistas (tabela 02) convergem em três categorias semelhantes às adotadas no estudo do Currículo de Ciências Biológicas (1993 apud Penick, 1998) e de Bybee (1997, apud Cachapuz 2011). Sendo a primeira a Alfabetização Científica funcional com objetivo no desenvolvimento de conceitos, centrando-se na aquisição de um vocabulário, palavras técnicas, envolvendo a Ciência e a Tecnologia; A segunda a Alfabetização Científica estrutural (conceitual e processual), na qual os alunos já atribuem significados próprios aos conceitos científicos, relacionando informações e fatos sobre Ciência e Tecnologia; e a terceira a Alfabetização Científica multidimensional, estende-se para além de vocabulário, preocupa-se com a apropriação de esquemas conceituais e métodos processuais, incluindo compreensões sobre Ciência.

Observamos que metade dos professores cursistas apresenta uma concepção multifuncional do conceito de Alfabetização Científica. Sobre essa questão, ressaltamos que uma subcategoria foi acrescentada após a formação e que outra teve uma redução no número de respostas. Aproximadamente um quinto dos professores deixou de apontar que a Alfabetização Científica seria somente conhecer o método científico ${ }^{3}$ e passou a considerar que o conceito desse tema está relacionado com a ideia de dar significado aos conhecimentos científicos. Embora não possamos identificar o momento de tal mudança de pensamento, visto que a formação teve tanto uma apresentação teórica quanto um estudo acadêmico textual que pode ter favorecido tal mudança conceitual na identificação do que significa Alfabetização Científica.

O texto científico adotado como leitura complementar enfatiza a importância do processo de compreensão sobre Alfabetização Científica para que possa ser contemplada em sala de aula. Seus autores (Cachapuz et al, 2011) mencionam algumas categorias citadas pelos docentes como a Alfabetização Científica voltada para o rigor do método científico e da formação do cientista. Portanto, consideramos que a discussão do tema e a proposta de leitura do texto influenciaram na mudança de concepção apresentada pelos professores.

Um aspecto relevante na mudança de concepção do que é alfabetizar cientificamente, reconhecendo que o método científico não é o ponto de partida para tal definição,

\footnotetext{
${ }^{3}$ Aqui compreendido como o conjunto de etapas ordenadas para a solução de um problema científico, partindo do levantamento de hipóteses.
} 
demonstra um movimento defendido por Bauer (1992), no qual o método científico não é a base para alfabetizar cientificamente. Para Bauer (1992), o contexto de se definir alfabetização científica está relacionada à palavra alfabetização e não ao conhecimento científico em si. Deste modo, o autor defende uma visão mais ampla de alfabetização científica, incluindo uma mudança de conduta e de postura dos sujeitos em suas atitudes e ações.

Essa concepção de alfabetização foi apresentada em duas subcategorias: a primeira delas está relacionada com a incorporação de saberes inerentes à ciência, incorporação que depende dos sujeitos envolvidos podendo gerar uma mudança de postura destes. A segunda explorando o sujeito atuante, reflexivo e crítico na sociedade. Essa concepção permite que os sujeitos sejam atores da formação e não sujeitos delimitados pelo conhecimento em si. Deste modo, essa concepção está diretamente ligada à visão de alfabetização descrita tanto por Bauer (1992) quanto por Shamos (1995). O significado de termos professores apresentando esse conceito é de suma importância para a formação de sujeitos.

Considerando que esses professores são formadores de cidadãos, a ideia de tornar os cidadãos reflexivos pode estar atrelada a uma apresentação da ciência de uma forma mais crítica, permitindo que os estudantes possam refletir sobre o conhecimento científico, sua concepção e suas diferentes formas de construir esse conhecimento.

No que se refere ao ensino que oportuniza o desenvolvimento da Alfabetização Científica, poucos docentes mudaram suas concepções durante o curso, sendo que as que mais chamam a atenção estão relacionadas ao ensino de Alfabetização Científica através de recursos específicos para a ação em sala de aula, concepção explicitada apenas no início da formação, a título de sondagem, não mencionada após a formação.

Nas interações dos professores e em suas respostas, observamos que muitos não constroem o discurso na primeira pessoa, aspecto evidenciado na última questão, quando os professores destacaram de que forma as ideias de Alfabetização Científica podem auxiliar a sua prática como professor. Os professores evidenciaram que o tema é importante; contudo, não incorporam na sua prática, visto que organizaram seu discurso na terceira pessoa, indicando que se trata do papel "do professor" e não necessariamente dele próprio.

Apesar disso, um dos aspectos que cinco destes docentes consideraram importante foi o de discutir se Alfabetização Científica está relacionada à possibilidade de interação e 
formação do aluno. Sasseron (2015) afirma a possibilidade de planejarmos e avaliarmos situações de ensino circunscritas no campo da $\mathrm{AC}$ a partir de indicadores que representam o envolvimento dos sujeitos no processo de resolução de problemas e de debates de questões de ordem científica:

Trata-se de habilidades vinculadas à construção de entendimento sobre temas das ciências que podem estar em processo em sala de aula e evidenciam o papel ativo dos estudantes na busca pelo entendimento dos temas curriculares das ciências (p. 57).

Nesse sentido, a Alfabetização Científica, trabalhada processual e reflexivamente na sala de aula, potencializa a formação do estudante à medida que participa de forma ativa e analítica sobre as questões de ordem científica que se põem urgentes na sociedade.

Um aspecto que surgiu após a formação está relacionado à ação do professor no que diz respeito a sua atitude em sala de aula e sua disposição quanto à promoção da Alfabetização Científica. Nesta questão, Pozo e Crespo (2009) salientam um desassossego nos professores quanto à abordagem científica do conhecimento. Esses autores apontam que a construção do conhecimento científico pode representar uma 'nova' cultura educacional com a elaboração do conhecimento científico e a aprendizagem em um processo construtivo. Deste modo, devem-se ter metas para a educação científica para uma melhor formação do estudante, para que uma cultura educacional científica seja "incorporada" no cotidiano destes sujeitos, necessitando assim, de uma atitude no professor mais construtiva.

\section{Conclusão}

A relação entre o ensino de Ciências e a promoção da Alfabetização Científica no contexto de formação continuada de professores é investigada nos discursos produzidos em um contexto de formação de professores no qual emergem evidências da $\mathrm{AC}$ em sua prática docente, bem como suas concepções.

Vale ressaltar que os professores manifestam interesse em desenvolver atividades que atendam a AC, contudo parece pertinente buscarmos as razões pelas quais sua implementação se apresenta de forma volátil. O que os impedem? O currículo? O cenário no qual a escola se encontra? A atividade diária de docência atrelada a metas e 
avaliações? O fato é que há diferentes formas de contemplarmos o trabalho pedagógico alicerçado na Alfabetização Científica, sendo que a construção de sequências didáticas contribui de forma significativa para o desenvolvimento da ação docente focada para essa finalidade.

É justamente nos contextos de formação continuada que encontramos a possibilidade de refletir junto aos professores sobre as diferentes concepções e conhecimentos que dizem respeito aos temas educacionais da atualidade, tendo em vista que nossos dados apontam uma mudança na percepção dos professores no tocante às concepções de Alfabetização Científica.

A formação continuada em questão possibilitou aos professores uma reflexão de suas práticas no tocante às atividades com a proposta de alfabetizar cientificamente os estudantes e, por tais motivos, evidenciamos a contribuição do presente estudo ao campo do Ensino de Ciências e da Formação Continuada de Professores, no escopo das práticas concernentes à Alfabetização Científica dos estudantes e dos professores para que o conhecimento seja explorado de forma crítica e reflexiva.

Conclui-se que muitos professores conseguiram ampliar sua visão sobre Alfabetização Científica e foram críticos ao analisar suas propostas de ação docente dentro dos eixos estruturantes e indicadores propostos para análise. Tal aspecto demonstra a capacidade de reflexão dos docentes bem como aspectos motivacionais para desenvolvimento de ações que contemplem a AC.

Dito de outra forma, apontamos que, nos contextos de formação continuada de professores, a discussão de Alfabetização Científica para o planejamento de práticas nas quais os estudantes sejam capazes de tomar decisões cientificamente fundamentadas e socialmente é relevante. Assumimos também que a polissemia em relação à Alfabetização Científica já apontada na literatura revela contradições e inquietações no campo do ensino das ciências, ensejando novas abordagens. 


\section{Referências Bibliográficas}

Araujo, E. S. N. N., Caluzi, J. J., \& Caldeira, A. M. A. (2006). Divulgação e cultura científica. In E.S.N.N. Araujo, J. J. Caluzi, \& A. M. A. Caldeira (org.). Divulgação científica e ensino de ciência: estudos e experiências (pp 15-34). São Paulo. Escrituras.

Bauer, H. H. (1992). Scientific Literacy and the Myth of the Scientific Method. Univ. of Illinois Press, Urbana and Chicago.

Bybee, R. W. (1997). Achieving scientific literacy: from purposes to practices. Portmounth: Heineman.

Cachapuz, A. et al. (2011). A necessária renovação do ensino das ciências. São Paulo: Cortez.

Chassot, A. (2002). Alfabetização científica: uma possibilidade para a inclusão social. III Cumbre Iberoamericana de Rectores de Universidades Públicas. Revista Brasileira de Educação, 21, 157-158.

Fourez, G. (2003). Crise no Ensino de Ciências. Investigações em Ensino de Ciências, 8(2), 109-123.

Gatti, B. A., \& Garcia, W. E. (org.). (2011). textos selecionados de Bernadete A. Gatti. Belo HOrizonte: Autêntica Editora.

Gil Perez, D., Montoro, I. F., Carrascosa, J., Cachapuz, A., \& Praia, J. (2001). Para uma imagem não deformada do trabalho científico. Revista Ciência \& Educação, 7(2): $125-153$.

Imbernón, F. (2010). Formação continuada de professores. Porto Alegre: Artmed.

Lankshear, C., \& Knobel, M. (2008). Pesquisa Pedagógica: do projeto à implementação. Tradução de Magda França Lopes. Porto Alegre: Artmed.

Lemke, J. (2006). Investigar para el futuro de la educación científica: nuevas formas de aprender, nuevas formas de vivir. Revista Enseñanza de Las Ciencias, 24 (1), 5 -12.

Moraes, R. (2003). Uma tempestade de luz: a compreensão possibilitada pela análise textual discursiva. Ciência \& Educação, 9(2), 191-211.

Moraes, R., \& Galiazzi, M. C. (2006). Análise textual discursiva: processo reconstrutivo de múltiplas faces. Ciência \& Educação, 12(1), 117-128.

National Research Council. (1996). National Science Education Standards. Washington D.C.: National Academy Press.

Penick, J. E. (1998). Ensinando "alfabetização científica". Educar em Revista, 14, 91113.

Pozo, J. I., \& Crespo, M. A. G. (2009). A aprendizagem e o ensino de ciências: do conhecimento cotidiano ao conhecimento científico. Porto Alegre: Artmed.

Roden, J., \& Ward, H. (2010). O que é ciência? In H. Ward et al. (orgs.) Ensino de Ciências (pp 13 - 33). Porto Alegre: Artmed.

Sasseron, L. H. (2015). Alfabetização Científica, Ensino por Investigação e Argumentação: Relações entre Ciências da Natureza e Escola. Revista Ensaio, 17 (especial), 49-67. 
Sasseron, L. H., \& Carvalho, A. M. P. (2008). Almejando a Alfabetização Científica no ensino fundamental: a proposição e a procura de indicadores do processo. Investigações em Ensino de Ciências, 13(3), 333-352.

Shamos, M. H. (1995). The myth of scientific literacy. New Brunswick: Rutgers University Press.

Vogt, C., \& Polino, C. (2003). Percepção pública de ciência: resultados da pesquisa na Argentina, Brasil, Espanha e Uruguai. Campinas: Editora Unicamp/Fapesp.

Patrícia da Silva Sessa é Professora adjunta da Universidade Federal do ABC. Doutora pela Faculdade de educação na USP. Pesquisadora no programa de Mestrado em Ensino e História das Ciências e da Matemática. Pesquisa na área de Formação de Professores; Alfabetização científica e Argumentação no Ensino de Ciências e Biologia.

Júlio Carvalho de Paiva é Mestrando do Programa de Pós Graduação em Biotecnociência na Universidade Federal do ABC. Possui graduação em Engenharia de Materiais, Engenharia Biomédica e em Bacharelado em Ciências e Tecnologia pela UFABC.

Emile Ferreira da Cunha Casasco é Mestre em ensino pelo Programa de Pós-graduação em Ensino e História das Ciências e Matemática pela Universidade Federal do ABC. Bacharel em Ciência e Tecnologia (2014), licenciada e bacharel em Ciências Biológicas (2015) pela UFABC. Pesquisadora nas áreas de Ensino de Botânica; Formação de Professores e Fisiologia Vegetal.

João Rodrigo Santos da Silva é Professor adjunto da Universidade Federal do ABC. Doutor pela Universidade de São Paulo. Pesquisador no programa de Mestrado em Ensino e História das Ciências e da Matemática. Pesquisa na área de Formação de Professores; Ensino de Ciências/Biologia em especial Botânica e Práticas de Ensino. 